\title{
Prokaryotic Expression, Purification and Identification of Human PDE9A Protein
}

\author{
Huan Rui \\ Laboratory of Biochemical Engineering, College of Pharmaceutical Engineering and Life \\ Sciences, Changzhou University, Changzhou 213003, China \\ E-mail: huan_rui2016@sina.com \\ Liqun Wang (Corresponding author) \\ Laboratory of Biochemical Engineering, College of Pharmaceutical Engineering and Life \\ Sciences, Changzhou University, Changzhou 213003, China \\ Tel: +86-0519-86334597; E-mail: wlq@cczu.edu.cn
}

Received: September 19, 2018 Accepted: November 8, 2018

doi:10.5296/jbls.v10i1.13667 URL: https://doi.org/10.5296/jbls.v10i1.13667

\begin{abstract}
Cerebral aggregation of beta amyloid plaques $(\mathrm{A} \beta)$ and neurofibrillary tangles is responsible for the onset of Alzheimer's disease (AD), and PDE9A inhibition rescues A $\beta$-induced deficits in synaptic plasticity and cognition. This study was aimed to express active PDE9A protein for subsequent inhibitor screening. The PDE9A gene was cloned from human cDNA by real-time polymerase chain reaction, and then the gene sequence and its amino acid sequence were analyzed on Lasergene. An inducible expression vector was constructed by enzyme digestion-seamless cloning and transformed into Escherichia coli BL21 (DE3) for PDE9A expression with isopropyl $\beta$-D-1-thiogalactopyranoside (IPTG) as an inducer. The recombinant protein was purified by Ni-NTA affinity chromatography and its activity was determined by a phosphodiesterase assay kit. It was found the open reading frame of PED9A was 1035 bp long, the deduced protein was composed of 345 amino acids, and its predicted isoelectric point was about 4.84 . The $E$. coli vector ST6-PDE9A successfully expressed the recombinant PDE9A protein in the supernatant of bacterial lysate. The optimal culture conditions were that the bacterium ST6-PDE9A was grown first in a lysogeny broth at $37^{\circ} \mathrm{C}$ to an $\mathrm{OD}_{600}$ of $0.6-0.8$ and then at $16^{\circ} \mathrm{C}$ for $40 \mathrm{~h}$ with the addition of $1 \mathrm{M}$ IPTG. Activity test showed PDE9A significantly hydrolyzed the substrate cyclic guanosine monophosphate. In conclusion, we constructed a prokaryotic expression vector and expressed active proteins, laying a solid foundation for screening PDE9 inhibitors.
\end{abstract}




\section{$\triangle$ Macrothink}

Keywords: Alzheimer's disease, phosphodiesterase 9, prokaryotic expression, purification, activity test

\section{Introduction}

Alzheimer's disease (AD) is a progressive, unremitting and neurodegenerative disorder that affects wide areas of the cerebral cortex and hippocampus (Masters et al., 2015). In AD patients, memory loss is accompanied by the formation of beta-amyloid (A $\beta)$ plaques and the appearance of pathological tau (Garcia-Osta, Cuadrado-Tejedor, Garcia-Barroso, Oyarzabal, $\&$ Franco, 2012). An estimated 24 million people worldwide have dementia, and the majority are thought to have AD (Ballard et al., 2011). The increasing number of affected individuals, the long duration of disability, and the rising costs of care for AD have posed heavy burdens to our society (Sibener et al., 2014). However, the etiology and pathogenesis of AD are still poorly understood. Evidence shows seven potential modifiable factors (diabetes, midlife hypertension, midlife obesity, physical inactivity, depression, smoking, and low educational attainment) contribute to the risk of AD (Norton, Matthews, Barnes, Yaffe, \& Brayne, 2014). Recent genome-wide association research has identified a number of risky genes that influence the susceptibility to late-onset AD (Jiang, Yu, Tian, \& Tan, 2013).

Phosphodiesterase (PDE) 9 is the most affinitive to cyclic guanosine monophosphate (cGMP) in the PDE family (Wang, Wu, Egan, \& Billah, 2003), which is distributed widely in the central nervous system. Aging is associated with an increase in PDE9 expression and activity and a decrease in cGMP concentration (Domek-Lopacinska \& Strosznajder, 2010). PDE9A inhibition can rescue $\mathrm{A} \beta$-induced deficits in synaptic plasticity and cognition (Kroker et al., 2014). The PDE9A inhibitor BAY 73-6691 can enhance early and late long-term potentiation (Lopez et al., 2012). Another PDE9A inhibitor PF-04447943 exhibits precognitive activity in several rodent models and synaptic stabilization in an amyloid precursor protein transgenic mouse model (Verhoest et al., 2012). However, a phase- 2 study demonstrates a 12-week PF-04447943 treatment did not improve cognition, behavior or global change compared with the placebo (Schwam et al., 2014). New PDE9A inhibitors are unwarranted to be potential drugs for AD treatment.

In this study, the PDE9A gene was cloned from the human body and a prokaryotic expression vector was constructed. Then PDE9A recombinant protein in Escherichia coli BL21(DE3) was expressed and then purified by $\mathrm{Ni}+$ column affinity chromatography. PDE9A activity was detected by a PDE-Glo ${ }^{\mathrm{TM}}$ phosphodiesterase assay kit.

\section{Methods}

\subsection{Primer Design}

The opening reading frame of the PDE9A gene was obtained from Pubmed. The nucleotide sequence corresponding to the 241-566 amino acid of subtype PDE9A was selected as the target to design a pair of primers. The following upstream and downstream primers were added to the SFI I restriction site:

\section{5'-GCTGCCCAGCCGGCGATGGCCCAAGCGGCCCCCACTTACCCCAAGTAC-3'}




\section{5'-GTCCTTGTAGTCATGGCCGACGGGGCCCTTCTTCTGTAACTCTTTC-3'.}

\subsection{Amplification and Analysis of Target Gene}

PCR was amplified using the cDNA of PDE9A as a template. In brief, $50 \mu \mathrm{L}$ of a PCR system

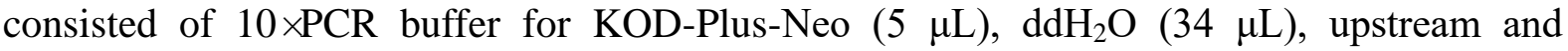
downstream primers (each $1 \mu \mathrm{L}), 2 \mathrm{mM}$ dNTPs $(5 \mu \mathrm{L}), 25 \mathrm{mM} \mathrm{MgSO}_{4}(3 \mu \mathrm{L}), \mathrm{cDNA}(1 \mu \mathrm{L})$, and KOD-Plus-Neo (TOYOBO, Japan, $1 \mu \mathrm{L}$ ). Reaction conditions were: $95^{\circ} \mathrm{C}, 2 \mathrm{~min}$; $94^{\circ} \mathrm{C}$, $30 \mathrm{~s}, 60^{\circ} \mathrm{C}, 30 \mathrm{~s}, 72{ }^{\circ} \mathrm{C}, 1 \mathrm{~min}, 30$ cycles; $72{ }^{\circ} \mathrm{C}$ for $10 \mathrm{~min}$ extension, cooling to $4{ }^{\circ} \mathrm{C}$. Then 5 $\mu \mathrm{L}$ of PCR products were detected via $1 \%$ agarose gel electrophoresis. The target gene fragment was cut off under an ultraviolet lamp and subjected to gel recovery using an AidQuick gel DNA extraction kit (Cat. No. DR01).

\subsection{Expression Vector Construction}

The target gene fragment and ST6 plasmid after SFI digestion were put together for seamless cloning in a $10 \mu \mathrm{L}$ system, which contained master assembly buffer mix $(5 \mu \mathrm{L})$, ST6 vector after SFI digestion $(2.5 \mu \mathrm{L})$, and the gel fraction $(2.5 \mu \mathrm{L})$. After complete mixing, the reaction system was placed in a water bath at $50{ }^{\circ} \mathrm{C}$ for $30 \mathrm{~min}$. Then the seamless cloned product was transformed into E. coli DH5a, which was plated on AMP (100 mg/mL)-containing plates and cultured overnight at $37^{\circ} \mathrm{C}$. Positive clones were selected by colony PCR and sent to Taihe Biotechnology Co., Ltd for sequencing.

\subsection{Induced Expression and Determination of Recombinant Protein}

The successfully sequenced colonies were shaken overnight at $37^{\circ} \mathrm{C}$. Plasmid PDE9A-ST6 was extracted with an Aidlab plasmid rapid extraction kit (Cat. No. PL02), converted into the E. coli BL21(DE3) strain, and frozen at $-80^{\circ} \mathrm{C}$. After that, $50 \mu \mathrm{L}$ of the frozen bacterial solution was placed in $5 \mathrm{~mL}$ of a terrific broth (LB) medium and activated overnight at $37^{\circ} \mathrm{C}$ for $14 \mathrm{~h}$. Then it was transferred to $100 \mathrm{~mL}$ of a fresh medium and cultured at $37^{\circ} \mathrm{C}$ until the $\mathrm{OD}_{600}$ reached 0.6-0.8. After that, $100 \mu \mathrm{L}$ of $1 \mathrm{M}$ isopropyl $\beta$-D-1-thiogalactopyranoside (IPTG) was added for $40 \mathrm{~h}$ of induction at $16^{\circ} \mathrm{C}$. The cells were collected, sonicated and then centrifuged at $12,000 \mathrm{rpm}$ for $30 \mathrm{~min}$. Then $10 \mu \mathrm{L}$ of each denatured sample (whole protein, supernatant, and precipitate) was taken for sodium dodecyl sulfate-polyacrylamide gel electrophoresis (SDS-PAGE) and detected by CBB-R250 staining.

\subsection{Purification and Activity Detection of Recombinant Protein}

The supernatant of the PDE9A-expressing strain was purified using $\mathrm{Ni}^{+}$column affinity chromatography (equilibration buffer: $10 \mathrm{mM}$ imidazole; washing buffers: 20 and $50 \mathrm{mM}$ imidazole; elution buffer: $250 \mathrm{mM}$ imidazole) and gel chromatography. Then the eluted recombinant protein was dialyzed against a solution containing no salt or imidazole (volume ratio: 1:100, liquid changed every $12 \mathrm{~h}$, dialysis for $36 \mathrm{~h}$ ). The purified protein was quantitatively analyzed by the bicinchoninic acid (BCA) method. The PDE9A activity was assayed using a PDE-Glo ${ }^{\mathrm{TM}}$ PDE assay kit (Promega) according to the manufacturer's instructions. The PDE9A activity was presented as the relative hydrolysis rate and normalized to the assayed proteins. 


\section{IMacrothink

\section{Results}

\subsection{Amplification of the Target Fragment}

The open reading frame of PED9A was $1035 \mathrm{bp}$ long, and the deduced protein was composed of 345 amino acids; its predicted isoelectric point was about 4.84. The target gene fragment was amplified by PCR and then detected by $1 \%$ agarose gel electrophoresis. Our results indicate the target band size is correct (Figure 1). The target protein was cleaved for gel recovery to construct a recombinant vector.

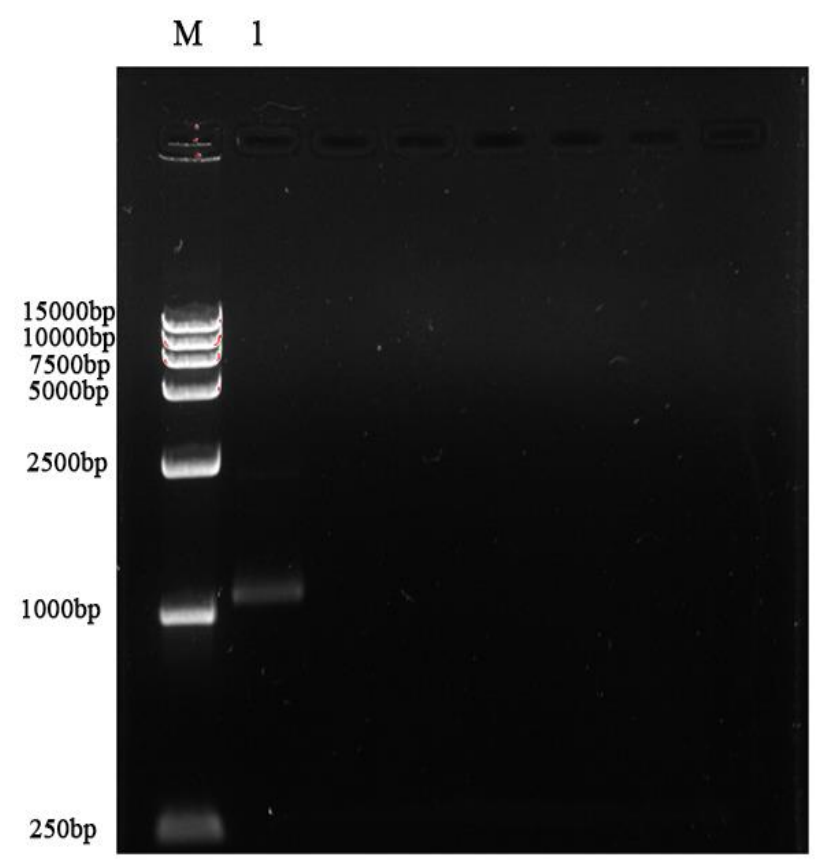

Figure 1. PCR amplification of target fragment. M: DL5000 DNA marker; 1-2: PDE9A

\subsection{Restriction Enzyme Digestion of Recombinant Vector}

The correctly-sequenced plasmid was subjected to restriction enzyme verification. Two bands appeared after digestion, and the electrophoresis position was consistent with the sizes of the ST6 vector (6402 bp) and the target fragment (1035 bp), indicating the prokaryotic expression vector of ST6-PDE9A was successfully constructed (Figure 2). 


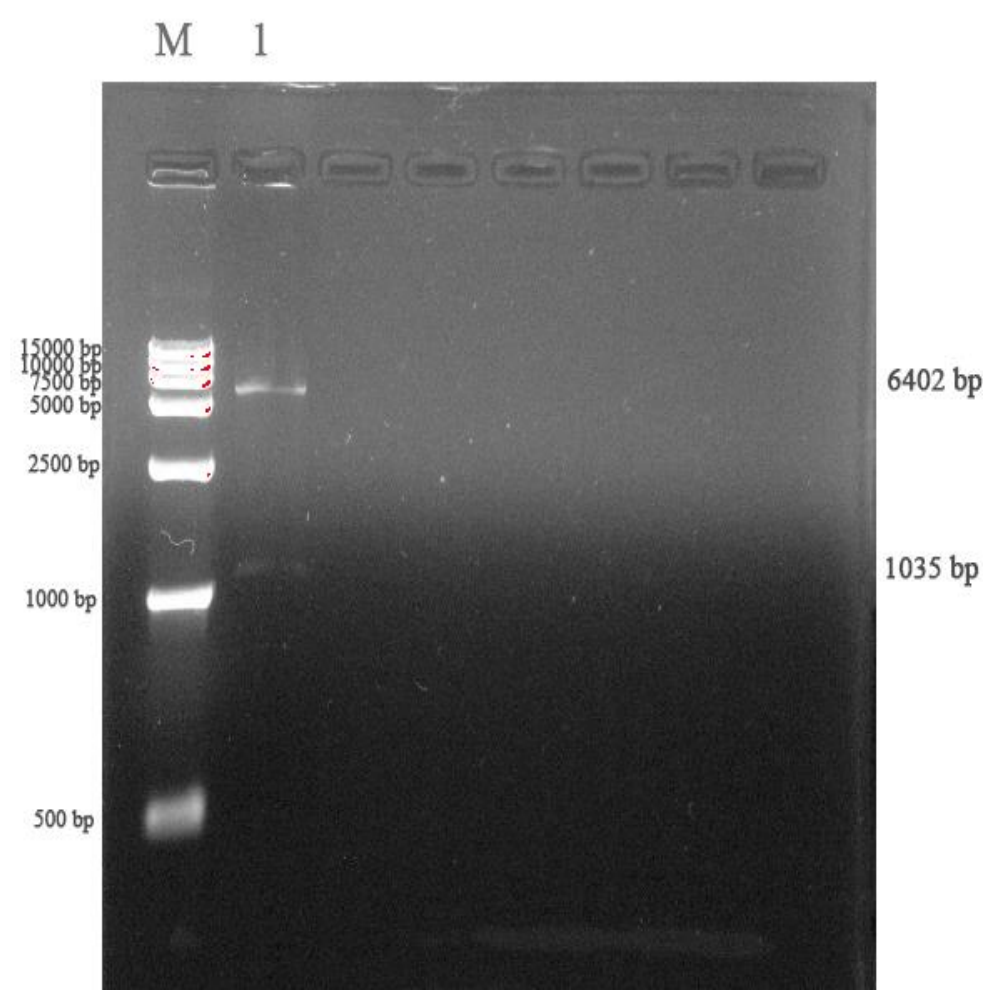

Figure 2. Identification of recombinant plasmid ST6-PDE9A by enzymatic digestion. M:

DL15000 DNA marker; 1: digestion results

\subsection{Soluble Analysis of Recombinant Protein PDE9A}

The cells after expression induction were collected by centrifugation and resuspended in phosphate buffer solution (PBS). After ultrasonication, the supernatant and precipitate were collected for SDS-PAGE. It was found the supernatant and precipitate showed clear bands around $39 \mathrm{KD}$, which was consistent with the expected band size, but the precipitate was more obvious. This result indicates the target protein mainly existed as inclusion bodies (Figure 3). 


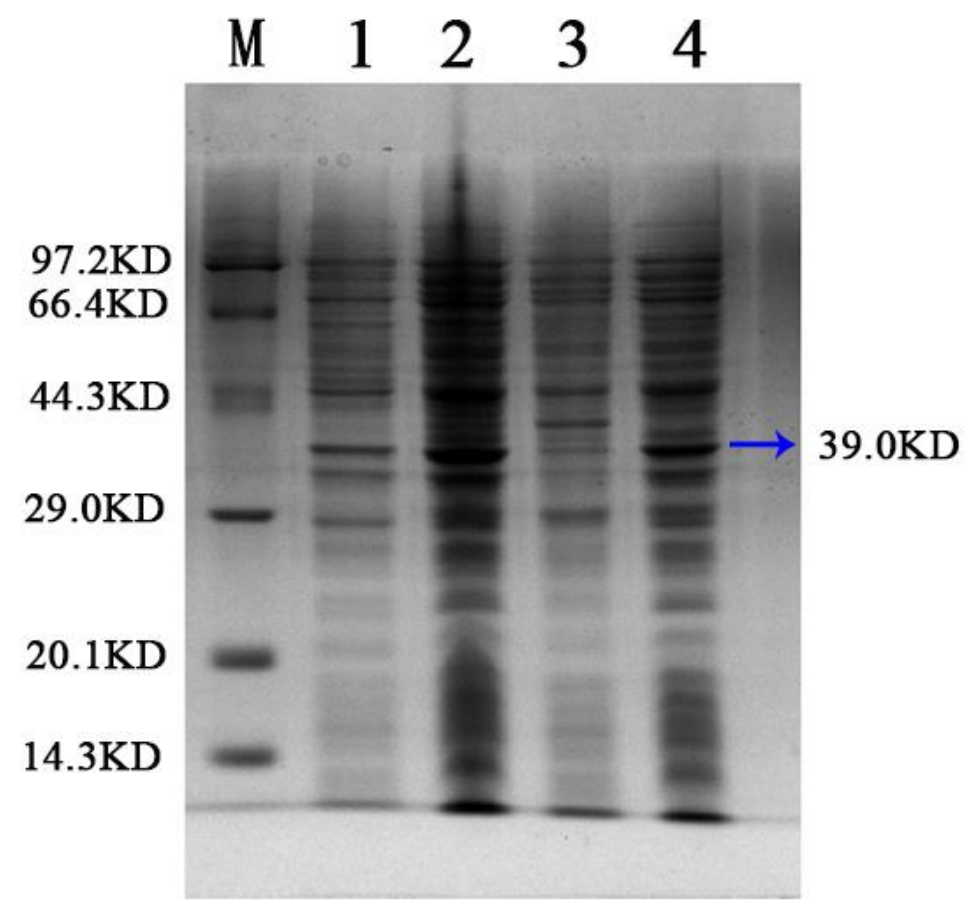

Figure 3. SDS-PAGE of solubility of expressed PDE9A. M: protein Marker; 1: no IPTG induction control; 2: bacteria protein induced for $40 \mathrm{~h}$; 3 : supernatant after ultrasonic disruption; 4: pellet after ultrasonic disruption.

\subsection{Protein Purification and Expression Condition Optimization}

After the $\mathrm{Ni}^{+}$column affinity chromatography, SDS-PAGE showed the recombinant protein eluted with $250 \mathrm{mM}$ imidazole was about $39 \mathrm{KD}$ in size, with clear and few bands (Figure 4).

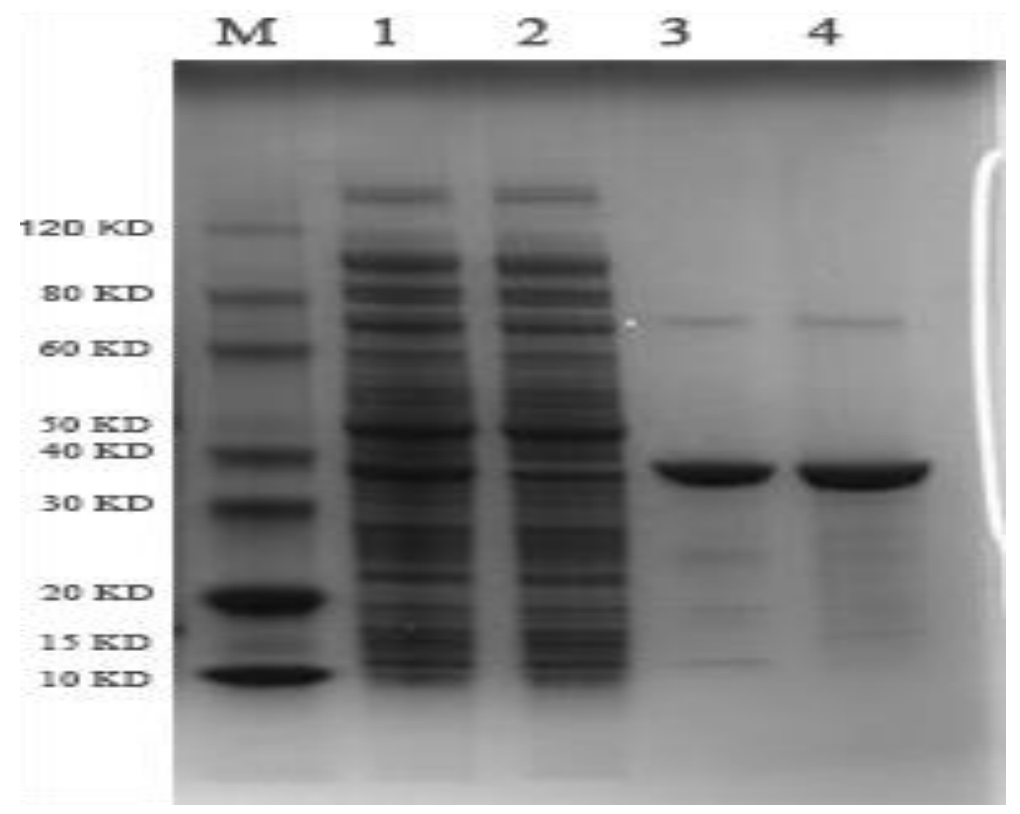

Figure 4. SDS-PAGE of purified PDE9A. M: protein marker; 1: supernatant after ultrasonic disruption; 2: flow through; 3, 4: 50 and $250 \mathrm{mM}$ imidazole eluted proteins, respectively. 


\section{Macrothink}

We explored the expression conditions of the transformed positive strains from multiple aspects (media, temperature, induction time, IPTG concentration). The expression induction media were tryptone yeast extract (YT), terrific broth (TB) and lysogeny broth (LB). The expression levels in YT were significantly higher than in TB and LB (Figure 5). The other best conditions were $16^{\circ} \mathrm{C}, 40 \mathrm{~h}$ and $1 \mathrm{M}$ IPTG.

a

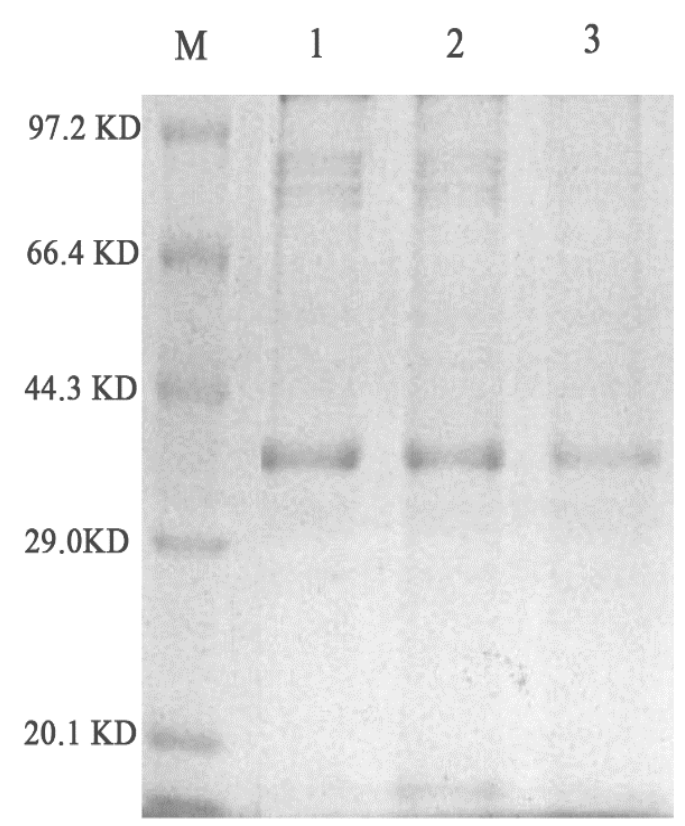

C

$\begin{array}{llll}\mathrm{M} & 7 & 8 & 9\end{array}$

$97.2 \mathrm{KD}$

$66.4 \mathrm{KD}$

44.3 KD

$29.0 \mathrm{KD}$

$20.1 \mathrm{KD}$

b

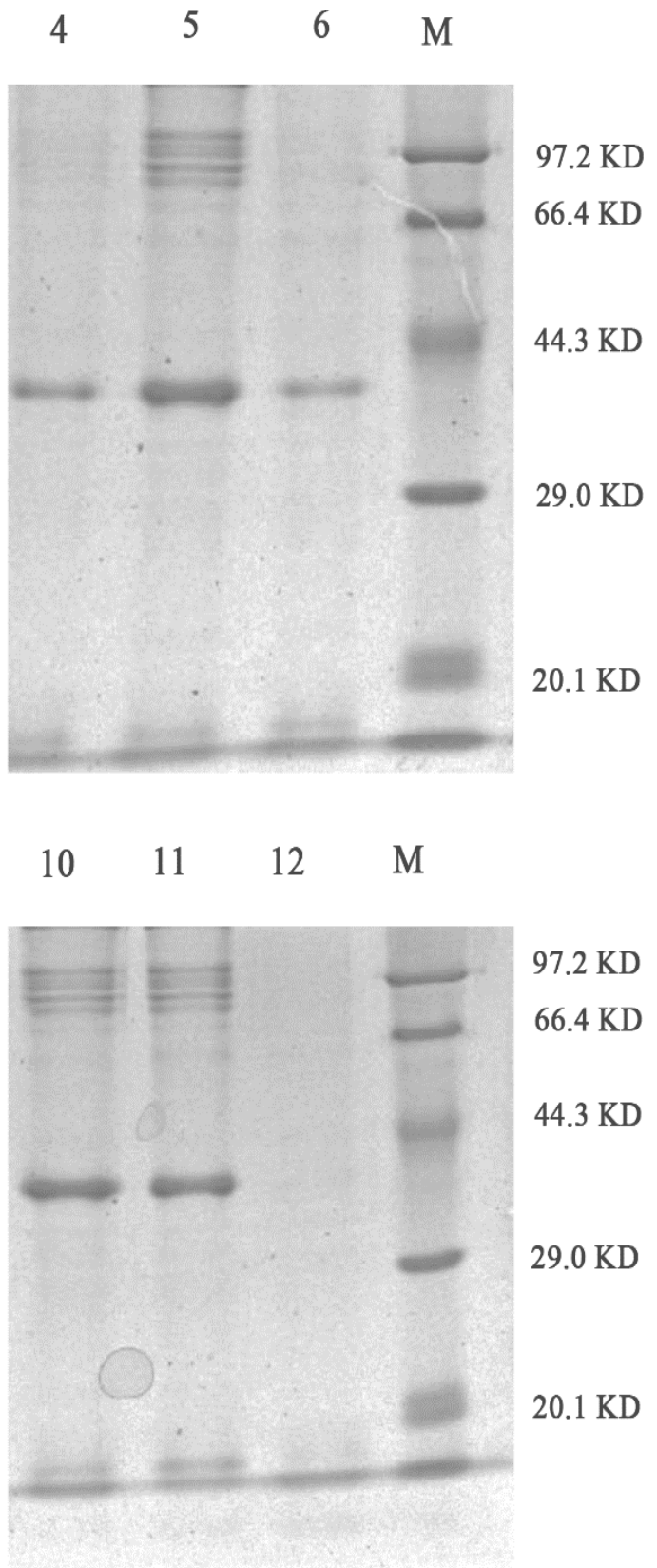

Figure 5. PDE9A protein expression induced in different media, temperatures, time, and IPTG concentrations. (a) 1-3: YT, TB and LB; (b) 4-6: 19, 16 and $13{ }^{\circ} \mathrm{C}$; (c) 7-9: 20, 30 and $40 \mathrm{~h}$; (d)10-12: 1, 0.5 and $0.1 \mathrm{M}$ IPTG. 


\section{Macrothink}

\subsection{Protein Activity Test}

The concentration of the recombinant protein after dialysis was $0.8046 \mathrm{mg} / \mathrm{mL}$. Then the the purified protein was diluted by 2, 4, 8, 16, 32, 64, 128 and 256 fold. The substrate cGMP, termination buffer, detection buffer and Kinase-GloB reagent were separately added. The luminescence after the complete reaction was detected on a microplate reader (Spark, Tecan, Switzerland). It was found the PDE9A protein at different concentrations could all hydrolyze the substrate cGMP. The substrate hydrolysis was accelerated with the increasing protein concentration. The $\mathrm{EC}_{50}$ was $0.08347 \mathrm{mg} / \mathrm{mL}$ identified by fitting the curve to GraphPad.

\section{EC50}

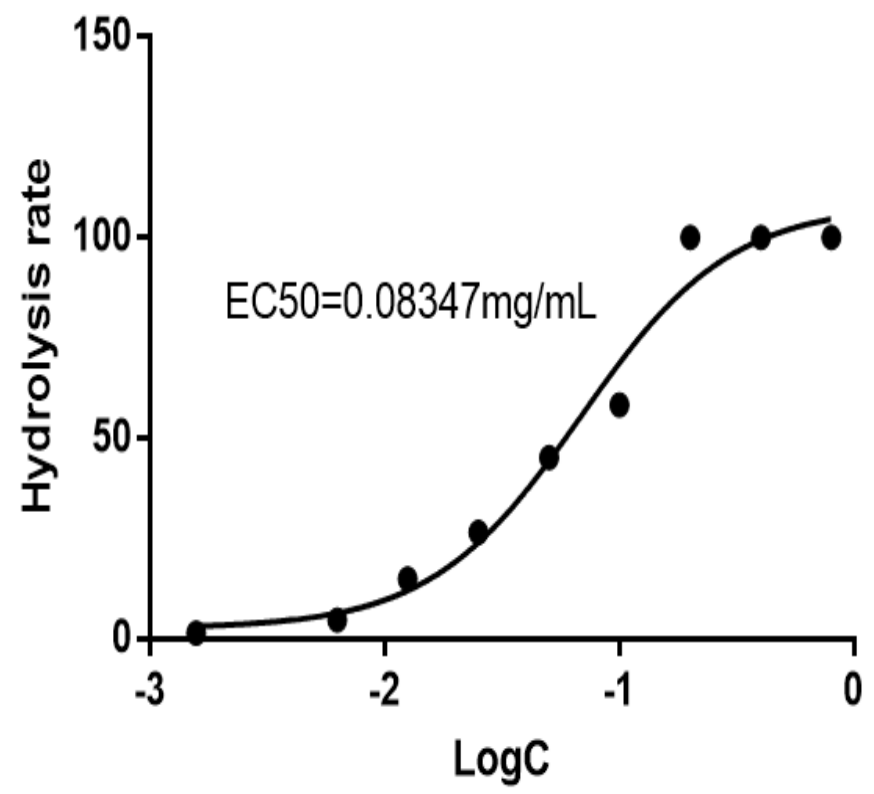

Figure 6. PDE9A enzyme activity assay

\section{Discussion}

The exponential rise in the number of $\mathrm{AD}$ cases imposes heavy emotional and financial burdens onto families and communities. So far, acetylcholinesterase inhibitors and memantine are the only drugs approved for AD treatment (Anand, Gill, \& Mahdi, 2014). These drugs only improve symptoms, but less affect the disease process (Anand et al., 2014). Insufficient understanding about the pathogenic process may be the main reason for the non-availability of effective treatment (Kumar, Singh, \& Ekavali, 2015). The cAMP and cGMP signalings are both involved in various cellular functions, including neuroplasticity and neuroprotection (Heckman, Wouters, \& Prickaerts, 2015). PDE inhibitors enhance cAMP and/or cGMP signaling via reducing the degradation of these cyclic nucleotides (Heckman, Blokland, Ramaekers, \& Prickaerts, 2015). PDE inhibitors have been considered to be therapeutic targets for AD. 
PDE9, a representative member of the PDE family, hydrolyzes cGMP and has many subtypes, such as PDE9A1, PDE9A2 and PDE9A3. Two PDE9A inhibitors (BAY 73-6691 and PF-04447943) reportedly enhance synaptic plasticity and cognitive function in rodents (Hutson et al., 2011; van der Staay et al., 2008). The PDE9 enzyme preparation and screening methods are quite different between these two inhibitors. For BAY 73-6691, PDE9A was recombinantly expressed in Sf9 insect cells using a pFAST-BAC baculovirus expression system (Invtrogen, CarIsbad, CA) (Wunder et al., 2005). The $\left[{ }^{3} \mathrm{H}\right]$ cAMP and $\left[{ }^{3} \mathrm{H}\right]$ cGMP scintillation proximity assays (GE healthcare, Buckinghamshire, UK) were used for enzyme inhibition research (Wunder et al., 2005). For PF-04447943, the rhesus PDE9A2 construct (GenBank ID\# FJ914626) was subcloned into a pcDNA3.3 TOPO vector (Invitrogen) and HEK 293 cells (Hutson et al., 2011). The PDE9A inhibitors were screened using a cGMP CL HitHunter assay kit (Hutson et al., 2011). The recombinant protein expressed in vitro by $E$. coli is an important tool in biotechnology research owing to the simple operation, low cost, high expression efficiency, stable product and easy identification. In this study, we selected the E. coli BL21(DE3) strain as a recipient bacterium, which was different from previous studies. In addition, $\left[{ }^{3} \mathrm{H}\right]$ cAMP or cGMP causes less environmental pollution and is unsuitable for use all the time. Our test kit for PDE9 activity is featured by low cost, high quality and little environmental pollution.

We also explored the conditions for inducing the expression of recombinant PDE9A protein. When the expression temperature is too high, the bacteria grow too fast and the target protein cannot be folded correctly to form more inclusion bodies, but the cell growth is slow at too low temperature. Thus, suitable temperature is conducive to protein expression. As reported, the bacterium (pET32a-PDE2) was grown first in $\mathrm{LB}$ at $37^{\circ} \mathrm{C}$ to an $\mathrm{OD}_{600}$ of 0.6-0.8 and then at $16^{\circ} \mathrm{C}$ for $6 \mathrm{~h}$ by adding $0.5 \mathrm{mM}$ IPTG (Zhu et al., 2013). On this basis, we optimized the protein expression conditions to be: YT, $16^{\circ} \mathrm{C}, 40 \mathrm{~h}$, and $1 \mathrm{mM} \mathrm{IPTG}$.

In conclusion, we successfully constructed a PDE9A-ST6 expression vector and expressed PDE9A at $16^{\circ} \mathrm{C}$ for $40 \mathrm{~h}$. Based on the optimal conditions, the purified PDE9A was obtained by $\mathrm{Ni}+$ column affinity chromatography. This study underlies future preparation and functional study of PDE9A protein inhibitors.

\section{References}

Anand, R., Gill, K. D., \& Mahdi, A. A. (2014). Therapeutics of Alzheimer's disease: Past, present and future. Neuropharmacology, 76 Pt A, 27-50.

https://doi.org/10.1016/j.neuropharm.2013.07.004

Ballard, C., Gauthier, S., Corbett, A., Brayne, C., Aarsland, D., \& Jones, E. (2011). Alzheimer's disease. Lancet, 377(9770), 1019-1031.

https://doi.org/10.1016/S0140-6736(10)61349-9

Domek-Lopacinska, K. U., \& Strosznajder, J. B. (2010). Cyclic GMP and nitric oxide synthase in aging and Alzheimer's disease. Mol Neurobiol, 41(2-3), 129-137.

https://doi.org/10.1007/s12035-010-8104-x 
Garcia-Osta, A., Cuadrado-Tejedor, M., Garcia-Barroso, C., Oyarzabal, J., \& Franco, R. (2012). Phosphodiesterases as therapeutic targets for Alzheimer's disease. ACS Chem Neurosci, 3(11), 832-844. https://doi.org/10.1021/cn3000907

Heckman, P. R., Blokland, A., Ramaekers, J., \& Prickaerts, J. (2015). PDE and cognitive processing: beyond the memory domain. Neurobiol Learn Mem, 119, 108-122. https://doi.org/10.1016/j.nlm.2014.10.011

Heckman, P. R., Wouters, C., \& Prickaerts, J. (2015). Phosphodiesterase inhibitors as a target for cognition enhancement in aging and Alzheimer's disease: a translational overview. Curr Pharm Des, 21(3), 317-331. https://doi.org/10.2174/1381612820666140826114601

Hutson, P. H., Finger, E. N., Magliaro, B. C., Smith, S. M., Converso, A., Sanderson, P. E., ... Parmentier-Batteur, S. (2011). The selective phosphodiesterase 9 (PDE9) inhibitor PF-04447943

(6-[(3S,4S)-4-methyl-1-(pyrimidin-2-ylmethyl)pyrrolidin-3-yl]-1-(tetrahydro-2H-py ran-4-yl)-1,5-dihydro-4H-pyrazolo[3,4-d]pyrimidin-4-one) enhances synaptic plasticity and cognitive function in rodents. Neuropharmacology, 61(4), 665-676.

https://doi.org/10.1016/j.neuropharm.2011.05.009

Jiang, T., Yu, J. T., Tian, Y., \& Tan, L. (2013). Epidemiology and etiology of Alzheimer's disease: from genetic to non-genetic factors. Curr Alzheimer Res, 10(8), 852-867. https://doi.org/10.2174/15672050113109990155

Kroker, K. S., Mathis, C., Marti, A., Cassel, J. C., Rosenbrock, H., \& Dorner-Ciossek, C. (2014). PDE9A inhibition rescues amyloid beta-induced deficits in synaptic plasticity and cognition. Neurobiol Aging, 35(9), 2072-2078.

https://doi.org/10.1016/j.neurobiolaging.2014.03.023

Kumar, A., Singh, A., \& Ekavali. (2015). A review on Alzheimer's disease pathophysiology and its management: an update. Pharmacol Rep, 67(2), 195-203.

https://doi.org/10.1016/j.pharep.2014.09.004

Lopez, S., Jouve, L., Turle-Lorenzo, N., Kerkerian-Legoff, L., Salin, P., \& Amalric, M. (2012). Antiparkinsonian action of a selective group III mGlu receptor agonist is associated with reversal of subthalamonigral overactivity. Neurobiol Dis, 46(1), 69-77.

https://doi.org/10.1016/j.nbd.2011.12.045

Masters, C. L., Bateman, R., Blennow, K., Rowe, C. C., Sperling, R. A., \& Cummings, J. L. (2015). Alzheimer's disease. Nat Rev Dis Primers, 1, 15056.

https://doi.org/10.1038/nrdp.2015.56

Norton, S., Matthews, F. E., Barnes, D. E., Yaffe, K., \& Brayne, C. (2014). Potential for primary prevention of Alzheimer's disease: an analysis of population-based data. Lancet Neurol, 13(8), 788-794. https://doi.org/10.1016/S1474-4422(14)70136-X

Schwam, E. M., Nicholas, T., Chew, R., Billing, C. B., Davidson, W., Ambrose, D., \& Altstiel, L. D. (2014). A multicenter, double-blind, placebo-controlled trial of the PDE9A 


\section{Macrothink}

inhibitor, PF-04447943, in Alzheimer's disease. Curr Alzheimer Res, 11(5), 413-421. https://doi.org/10.2174/1567205011666140505100858

Sibener, L., Zaganjor, I., Snyder, H. M., Bain, L. J., Egge, R., \& Carrillo, M. C. (2014). Alzheimer's Disease prevalence, costs, and prevention for military personnel and veterans. Alzheimers Dement, 10(3 Suppl), S105-110. https://doi.org/10.1016/j.jalz.2014.04.011

van der Staay, F. J., Rutten, K., Barfacker, L., Devry, J., Erb, C., Heckroth, H., ... Hendrix, M. (2008). The novel selective PDE9 inhibitor BAY 73-6691 improves learning and memory in rodents. Neuropharmacology, 55(5), 908-918.

https://doi.org/10.1016/j.neuropharm.2008.07.005

Verhoest, P. R., Fonseca, K. R., Hou, X., Proulx-Lafrance, C., Corman, M., Helal, C. J., ... Liras, S. (2012). Design and discovery of

6-[(3S,4S)-4-methyl-1-(pyrimidin-2-ylmethyl)pyrrolidin-3-yl]-1-(tetrahydro-2H-pyr

an-4-yl)-1,5-dihydro-4H-pyrazolo[3,4-d]pyrimidin-4-one (PF-04447943), a selective brain penetrant PDE9A inhibitor for the treatment of cognitive disorders. J Med Chem, 55(21), 9045-9054. https://doi.org/10.1021/jm3007799

Wang, P., Wu, P., Egan, R. W., \& Billah, M. M. (2003). Identification and characterization of a new human type 9 cGMP-specific phosphodiesterase splice variant (PDE9A5). Differential tissue distribution and subcellular localization of PDE9A variants. Gene, 314, 15-27. https://doi.org/10.1016/S0378-1119(03)00733-9

Wunder, F., Tersteegen, A., Rebmann, A., Erb, C., Fahrig, T., \& Hendrix, M. (2005). Characterization of the first potent and selective PDE9 inhibitor using a cGMP reporter cell line. Mol Pharmacol, 68(6), 1775-1781. https://doi.org/10.1124/mol.105.017608

Zhu, J., Yang, Q., Dai, D., \& Huang, Q. (2013). X-ray crystal structure of phosphodiesterase 2 in complex with a highly selective, nanomolar inhibitor reveals a binding-induced pocket important for selectivity. J Am Chem Soc, 135(32), 11708-11711.

https://doi.org/10.1021/ja404449g

\section{Copyright Disclaimer}

Copyright for this article is retained by the author(s), with first publication rights granted to the journal.

This is an open-access article distributed under the terms and conditions of the Creative Commons Attribution license (http://creativecommons.org/licenses/by/3.0/). 